\title{
Government Online: An E-Government Platform to Improve Public Administration Operations and Services Delivery to the Citizen
}

\author{
Athanasios Drigas and Leyteris Koukianakis \\ NCSR 'Demokritos', \\ Institute of Informatics and Telecommunications, \\ Net Media Lab, \\ Agia Paraskevi, 153 10, Athens, Greece \\ \{dr, kouk\}@iit.demokritos.gr
}

\begin{abstract}
E-government includes fast and improved citizen service from a quantitative and qualitative point of view, as well as the restructuring and reengineering of organizations and their services, through the increased usage and exploitation of the capabilities and services of ICT's and the Internet. The escalation of the e-government services begins with easy access to governmental information and passes through the e-transactions between citizens and the public organization and reaches the electronic delivery of the requested document. A prerequisite in order to support the aforementioned e-government services "layers" is the development of an electronic system, which supports e-protocol, e-applications/e-petitions and internal organizational function of the public organization. In addressing the above context, this article presents an e-government structure which supports and provides the aforementioned e-government services "layers" in order to provide public information dissemination, accept electronic document submissions, manage them through eprotocol and support the operations through the appropriate electronic structure.
\end{abstract}

Keywords: e-government, e-protocol, e-transactions, governmental functions, e-tools, e-applications, e-petitions, e-delivery, ICT.

\section{Introduction}

E-government constitutes an extensive area of knowledge, principles and policies, and thus among others includes the following ideas. Firstly, user centric services are designed from the perspective of the user. This implies taking into account the requirements, priorities and preferences of each type of user. Efficient, high quality public services for all are fundamental for economic growth, more and better jobs and affordable solidarity in Europe.

E-government should now realize its promise of measurably more efficiency, more effectiveness for the users, higher quality services, full accountability, better democratic decisions, and inclusive services for all. Widespread modernization and 
innovation of public administrations must become a reality. The focus is to move from readiness to impact and transformation. The emphasis should shift from online availability to achieving impact and wider user take-up, using more comprehensive benchmarking. Organisational innovation includes the improvement of human resources and skills. These "human" factors are essential to be able to make progress on organisational innovation but - most importantly - they should also be a driving force to turn organisational innovation into a continuous process. E-government refers to the federal government's use of information and communication technologies (such as Wide Area Networks, the Internet, and mobile computing) to exchange information and services with citizens, businesses, and other arms of government. It originates from penetration of ICTs within the governmental domain. E-government transforms the traditional and well known shape of governmental structure, services and operations to a new figure which affects strongly the e-citizen transactions with the governmental services. More and more governments are using information and communication technologies and especially the Internet or web-based applications, to provide services among governmental agencies and citizens, businesses, employees and other nongovernmental organizations [1],[2]. Just as e-learning [3],[16],[17], ehealth and e-commerce [4], e-government represents the introduction of a great wave of technological innovation as well as government reinvention. E-government uses the most innovative information and communication technologies, particularly webbased applications, to provide citizens and businesses with access to governmental information and services, to improve the quality of the services and to develop and provide greater opportunities to citizens to participate in democratic institutions and processes [5],[6]. This includes transactions between government and business, government and citizen, government and employee, and among different units and levels of government like justice, taxation, welfare, social security, procurement, intragovernmental services etc [7],[8],[9],[10],[11],[12]. All these require technical policies and specifications for achieving interoperability, security and information systems coherence across the public sector [13],[14],[15].

The above context constitutes a basic body of knowledge for the design and development of e-government applications. On this basis, and towards a modular design of the electronic transactions, we analytically specified, designed, and developed a generic e-government environment that is based on a highly interactive, user-case model (citizen, employee, and administrator) and a flexible-interoperable scheme of assistive communication tools.

\section{Structure of the E-Government Environment}

The e-government environment consists of three systems: A web portal, the eprotocol system and finally the e-applications/e-petitions system. The last two will be described as one, since the latter may be considered as an extension of the e-protocol system. The governmental organization consists of six departments (planning, havoc compensation, housing, protocol, finances and research). Each department has one director and a large number of employees. 


\subsection{Web Portal's Environment Tools}

The web portal environment includes tools that offer flexibility and adaptability depending on their use. The design of these tools is based on web services, such as discussion forums, chat, message box, e-libraries, which are widespread in the public web community. These tools are distinguished into two groups: "informative" and "communicative"'. On the one hand, the "informative", tools include services related to the information of governmental functions and their presentation. On the other hand, the "communicative" tools include services that allow the communication of users belonging to the same or different group (session level). The web portal environment enables the management of these tools according to the user groups' permission. More explicitly, the "informative" tools are the following: announcements, frequently asked questions (F.A.Q.) and e-libraries. Respectively, the "communicative" tools are: discussion forums, message boxes, chat and e-requests. Finally, it must be noted that the environment relates the tools according to the specific user level permissions. These levels are analyzed in the sections to follow.

\subsection{User Levels}

Seven user levels are distinguished (Fig.1) in the web portal environment. Different supporting tools exist in each one of them.

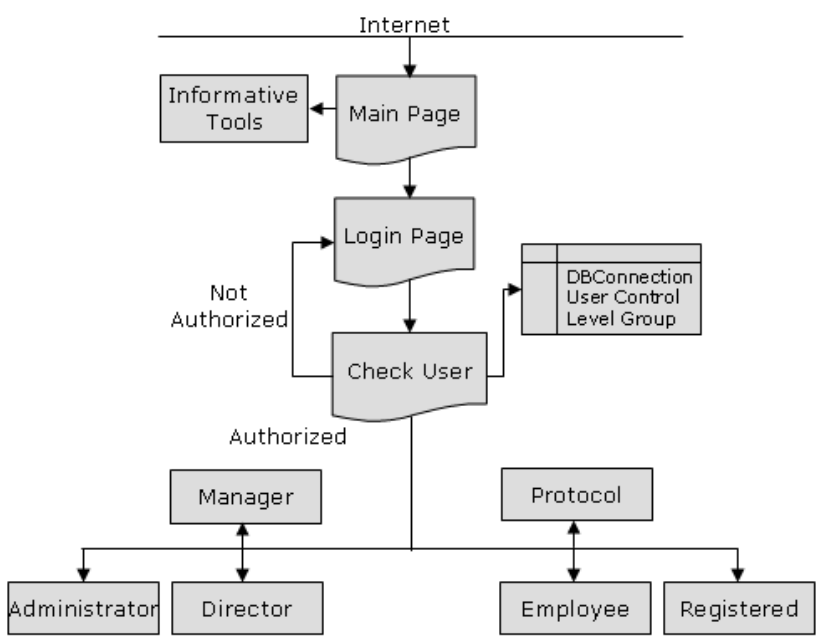

Fig. 1. User Levels

Depending on the corresponding use, these levels have also a different role: Administrator, Manager, Director, Employee, Protocol Administrator (Employee), Registered (Authorized) User and Unauthorized User (Guest). Each of them interacts with the other through the "informative" and "communicative" tools related to each level.

The administrator coordinates and manages the e-government application through the administrative tools. The administrator determines which user level-group has the 
permission to use the corresponding "informative" and "communicative" tools. Moreover, the administrator can communicate with the other user levels in order to solve issues and has the privilege of updating the system. Finally, the administrator decides about the preparation, design and diffusion of the electronic content to the citizens. Through user friendly and interactive ICT web tools, the administrator authors the governmental content.

The Manager, Director and Employees user levels are described together, as they incorporate many similarities. The manager decides about the preparation, design and diffusion of the electronic content. Moreover, through the communicative tools, the employees cooperate with the directors, the directors with the manager and the manager with the administrator with respect to discussing solutions to problems and to exchange ideas for the better functionality of the system. Finally, these three user levels play an important and diverse role in the e-protocol chain, which will be described later.

The Protocol Administrator (Employee) is responsible for the e-protocol system. Besides the "informative" and "communicative" tools, he/she has the ability to view, change (under conditions) and add applications/petitions to the e-protocol system. The applications/petitions are fully categorized and new categories can be created. The Registered (Authorized) Users have the ability to see and change specific information regarding their account, can view the progress of their applications/petitions and finally, they can make new applications/petitions that are supported by the e-application/e-petition system.

Finally, Unauthorized Users (Guests) can enter and search the data structure as a means of gathering important information. Finally, they may be informed about the news and events through the news and calendar service.

\section{User Tools and Services}

\subsection{Administrative Tools}

The environment provides administrative tools that are divided into two groups as follows: Management of the web portal system and management of the e-protocol and e-applications/e-petitions system. The management of the web portal system incorporates management of the "informative" services and management of the "communicative" services (Fig. 2). The management of the informative services is an important issue, as through it the administrator has the flexibility to manage the following ontologies: The users, the main menu description, the e-library, announcements and finally, the frequently asked questions (F.A.Q.). The environment tools enable the administrator to organize the informative content.

Correspondingly, the communicative services group consists of interactive forms through which the administrator manages chat session, the discussion forum and finally, the message box.

Management of the e-protocol and e-applications/e-petitions systems incorporates management of the petitions, their categories and their deadlines. The transactions executed in each group concern retrieval, insertion and update of the corresponding data. All web requests/responses are carried out through interactive and user-friendly forms. 


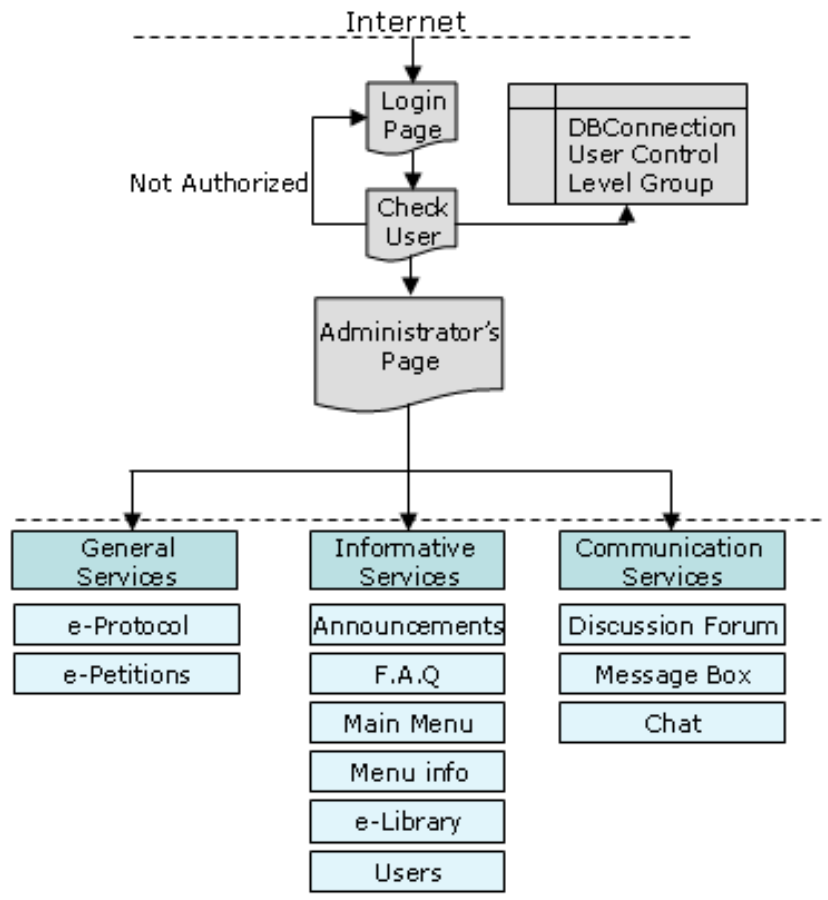

Fig. 2. Administrative Tools

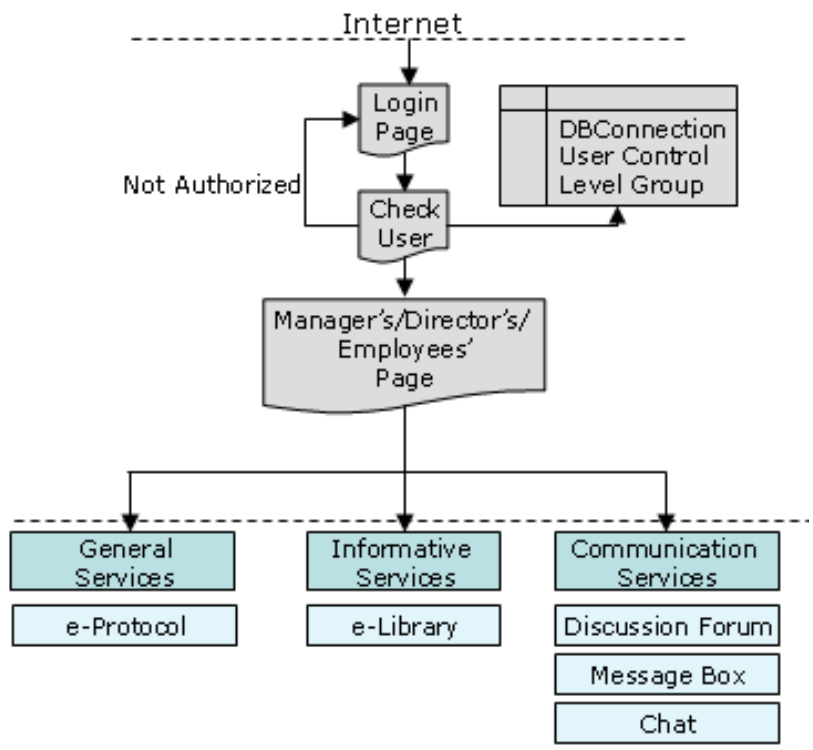

Fig. 3. Manager / Director / Employees Environment Tools 


\subsection{Manager-Director-Employees Environment Tools}

The environment tools (Fig. 3) for these user levels are divided into three groups: Communicative, Informative and General Services. The group of communicative services is the one that enables these three user levels to communicate with the other user levels. The tools that employ these tasks are: the discussion forum, the message box, and chat. The second group of the informative services consists of tools that enable the fast access and management of the electronic content. This content cannot be accessed by unauthorized users. The general services group includes tools that are different for each user level and play an essential role in the e-protocol chain.

\subsection{Protocol Employee Environment Tools}

The environment tools of this user level (Fig. 4) are similar to the ones mentioned in 3.2. In addition, this level has extended tools regarding the e-protocol system. The protocol employee has more privileges in the e-protocol system and can also interact with the e-petitions system. This level is the starting and ending point in the eprotocol chain.

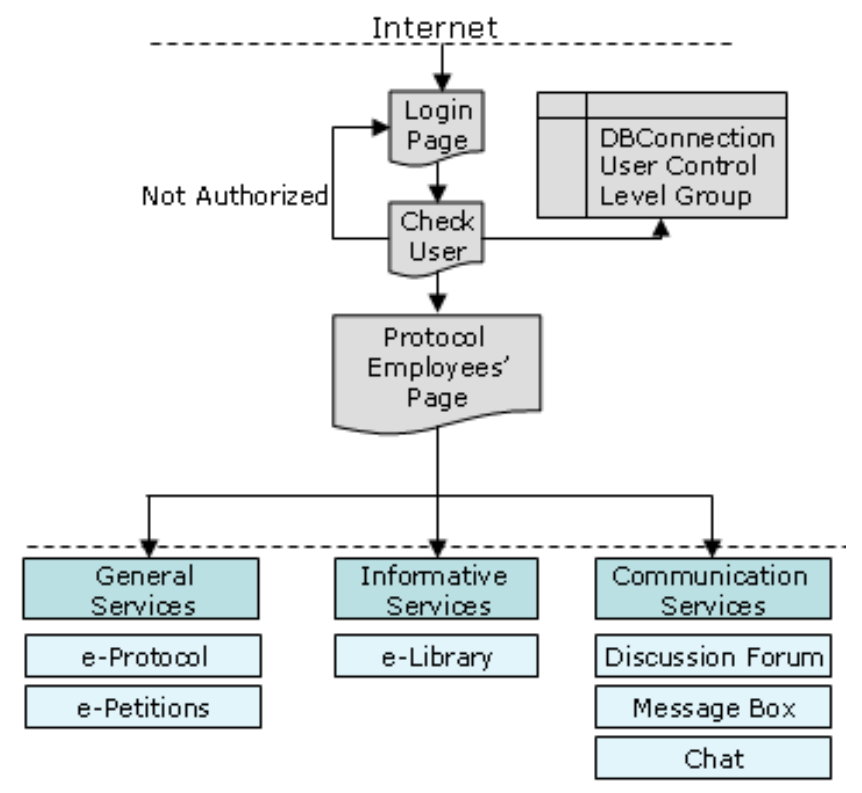

Fig. 4. Protocol Administrator Environment Tools

\subsection{Registered - Authorized Users Environment Tools}

The registered-authorized users have permission to interact with the e-Petitions system (Fig. 5). They can submit an application to the agency, as long as it is supported by the system. Moreover, the registered-authorized users have the ability to track the status of the applications they had submitted in the past. Finally, they can view and change some of their account information. 


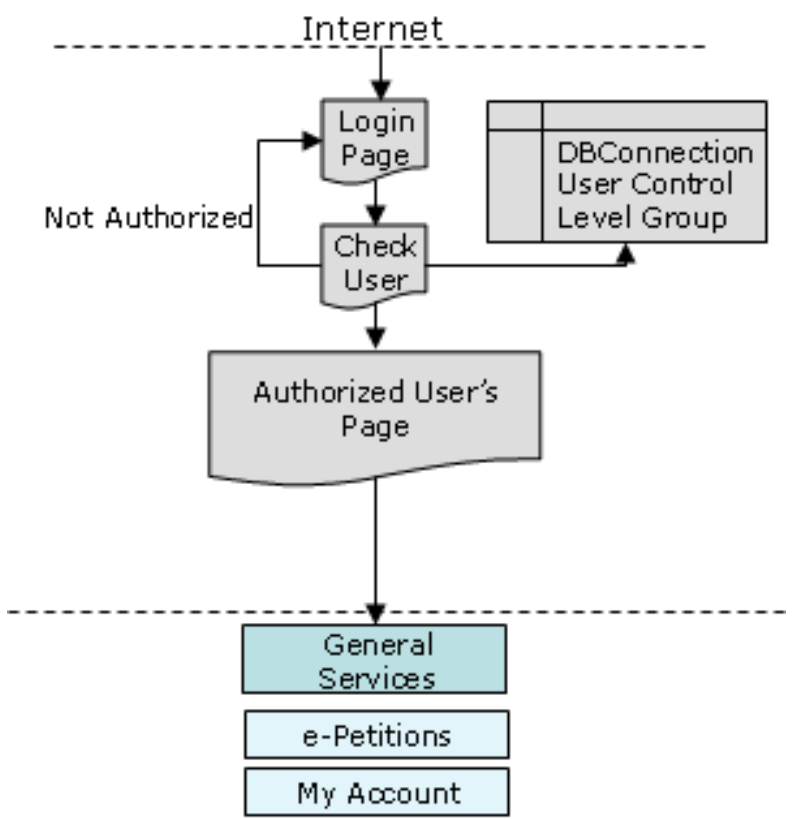

Fig. 5. Registered - Authorized Users Environment Tools

\subsection{Guest - Unauthorized Users Environment Tools}

The Guests - Unauthorized Users, on the other side, can browse the web portal in order to obtain valuable information regarding the agency and/or the issue(s) they wish to apply for. In order to apply, the guests-unauthorized users have to create an account (register) and interact with the e-Petitions system.

\section{Structure Presentation}

\subsection{General Description}

The presented environment is used as the web portal of the Earthquake victims' Compensation Agency. The application serves as a means for the electronic collaboration of the agency's employees as well as for the general informing of citizens regarding the e-services. The basic contribution is the application of the communicative services (discussion forum, chat, message box) as a means of central-based communication of the agency with its employees and with the citizens. The main objective of the developed infrastructure is the diffusion of information from the agency to everyone and the improvement of the e-services to the citizens. The portal's contribution with respect to information and valorization is the diffusion of the agency's information and services to the simple Internet user. 


\subsection{The Core of the e-Protocol System}

The e-Protocol system accepts petitions from various sources such as deposits, faxes, standard mail, e-mail and from the Internet. In the case where the petition's source is the Internet, the applicant receives a confirmation number and directions in order for his/her application to be fully registered. This mechanism is intended to avoid fake applications entering the e-protocol system.

Once a new petition has entered the system, the procedure shown in Fig.6 is applied. The application is regarded as a new task that must be assigned to someone in order to process it. In the beginning it is assigned by the Protocol Administrator to the Department Manager, who in his/her turn assigns it to one or more Department Directors and the latter to one or more employees. Finally, it reaches the Protocol Administrator who completes it and sends it to the Correspondence Office. All steps are automated and the system has been designed so as to minimize the need of human intervention. For instance, the users are notified by the system when a new task is assigned to them. The transactions are made under secure communications (SSL) and there is an idle timeout of 20 minutes. If there is no activity during this period, the system automatically logs out the user.

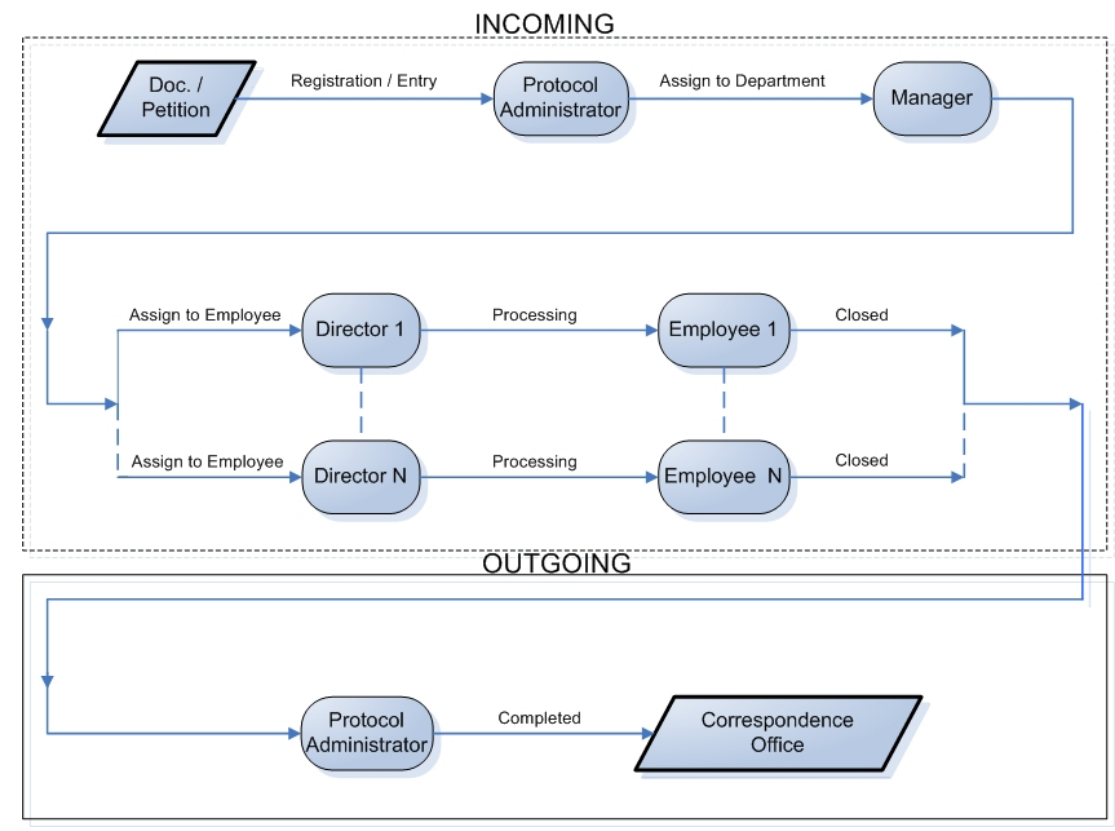

Fig. 6. E-Protocol Chain

\section{Conclusions}

E-government is the challenge for European Governments, to simplify, accelerate and improve, the delivery of the governmental circle services and facilities to the citizen. 
According to Lisbon's Ministerial Meeting, EU groups of policies and initiatives, known as E-Europe, among other policies and priorities for the Information Society, give emphasis on Government online. This ensures that citizens have easy access to government information, services and decision-making procedures online. The big issue for e-government is to use Information and Communication Technologies (ICT's) to develop efficient services for European citizens. In particular, the basic aim is to develop Internet-based services to improve public access to information and public services, to improve public administration transparency through the Internet and to ensure that citizens have access to essential public data to allow them to take part in the decision-making process. Moreover, another goal is to ensure that electronic technology is fully used within public administration, with secure software and usage of secure layers in order to guarantee and reach some security standards.

E-government refers to electronic access to government information and services. As it has been mentioned before, the e-government idea includes fast and improved citizen service from a quantitative and qualitative point of view, as well as the restructuring and reengineering of the providing organization and its services, through the increased usage and exploitation of the capabilities of the information and communication technologies and especially through the facilities and services of the Internet. The escalation of the e-government services begins with the easy dissemination and easy access of the citizen to the governmental information and passes through the electronic transactions between the citizen and the public organization and reaches the electronic delivery of the requested document by the public organization to the citizen. An obvious prerequisite, in order to support the above "layers" of the egovernment services is the development of an electronic infrastructure which is able to support e-protocol, e-applications/e-petitions and internal organizational function of the public organization. In addressing the above context, this article presented an egovernment structure which supports and provides the aforementioned "layers" of the e-government services. This e-government structure, which introduces the notion and practicalities of electronic technology into the various dimensions and ramifications of government, has been developed by Net Media Lab of N.C.S.R. "Demokritos" for a Hellenic Public Organization, in order for the latter, to provide public information dissemination, accept electronic document submissions and manage them via eprotocol and support all the operations via the appropriate electronic structure which supports easy communication among the organization's departments as well as robust and user-friendly document management, storage, search, retrieval, handling and delivery.

Summing up, this paper presented an e-government environment based on information and communications tools. Our contribution is based on the proposal of a generic electronic scheme that enables distant collaboration of the agency's employees and the e-citizen. The included tools serve communicational and informative governmental functions through a user-friendly, interoperable and distributed webbased architecture. It must be noted that two basic axes are served. The first is the communication of the employees and the e-citizen, 24 hours a day, and the econtent development for different user levels. The second axe includes the delivery of e-services to the citizen. 


\section{References}

1. Metaxiotis, K., Psarras, J.: E-Government: New Concept, Big Challenge, Success Stories. Electronic Government: An International Journal 1(2), 141-151 (2004)

2. Fang, Z.: E-Government in Digital Era: Concept, Practice, and Development. International Journal of the Computer, the Internet and Management 10(2), 1-22 (2002)

3. Drigas, A., Vrettaros, J., Kouremenos, D., Stavrou, P.: E-learning Environment for Deaf people in the E-Commerce and New Technologies Sector. WSEAS Transactions on Information Science and Applications 1(5), 1189 (2004)

4. Drigas, A., Koukianakis, L.: A Modular Environment for E-Learning and E-Psychology Applications. WSEAS Transactions on Information Science and Applications 6(3), 2062 2067 (2004)

5. Xenakis, A., Macintosh, A.: G2G Collaboration to Support the Deployment of E-Voting in the UK: A Discussion Paper. In: Traunmüller, R. (ed.) EGOV 2004. LNCS, vol. 3183, pp. 240-245. Springer, Heidelberg (2004)

6. Macintosh, A., Robson, E., Smith, E., Whyte, A.: Electronic Democracy and Young People. Social Science Computer Review 21(1), 43-54 (2003)

7. Kelly, E.P., Tastel, W.J.: E-Government and the Judicial System: Online Access to Case Information. Electronic Government: An International Journal 1(2), 166-178 (2004)

8. Barnes, S.J., Vidgen, R.: Interactive E-Government Services: Modelling User Perceptions with eQual. Electronic Government: An International Journal 1(2), 213-228 (2004)

9. Henman, P.: E-Government and the Electronic Transformation of Modes of Rule: The Case of Partnerships. Journal of Systemics, Cybernetics and Informatics 2(2), 19-24 (2004)

10. Verma, S.: Electronic Government Procurement: A Legal Perspective on the Indian Situation. Electronic Government: An International Journal 1(3), 328-334 (2004)

11. Wild, R.H., Griggs, K.A.: A Web Portal/Decision Support System Architecture for Collaborative Intra-Governmental Planning. Electronic Government: An International Journal 1(1), 61-76 (2004)

12. Kanthawongs, P.: An Analysis of the Information Needs For E-Parliament Systems. WSEAS Transactions on Information Science and Applications 1(5), 1237-1242 (2004)

13. Borras, J.: International Technical Standards for E-Government. Electronic Journal of E-Government 2(2), 75-80 (2004)

14. Chen, Y.S., Chong, P.P., Zhang, B.: Cyber Security Management and E-Government. Electronic Government: An International Journal 1(3), 316-327 (2004)

15. Abie, H., Foyn, B., Bing, J., Blobel, B., Pharow, P., Delgado, J., Karnouskos, S., Pitkanen, O., Tzovaras, D.: The Need for a Digital Rights Management Framework for the Next Generation of E-Government Services. Electronic Government: An International Journal 1(1), 8-28 (2004)

16. Drigas, A., Vrettaros, J., Kouremenos, D.: An E-Learning Management System for the Deaf People. WSEAS Transactions on Advances in Engineering Education 1(2), 20-24 (2005)

17. Drigas, A.: E-Course Support and Delivery for E-Psychology. WSEAS Transactions on Advances in Engineering Education 1(2), 25-28 (2005) 